\title{
Relationship to Ratio of Correct Information Unit and Cognitive Functions in Patients with Amnestic MCI and EAD
}

\author{
Hyunjoo Choi ${ }^{a}$, Jun-Young Lee ${ }^{b}$ \\ ${ }^{a}$ Department of Communication Disorders, Korea Nazarene University, Cheonan, Korea \\ ${ }^{b}$ Department of Psychiatry, Seoul National University College of Medicine E SMG-SNU Boramae Hospital, Seoul, Korea
}

Correspondence: Hyunjoo Choi, $\mathrm{PhD}$

Department of Communication Disorders, Korea

Nazarene University, 48 Wolbong-ro, Seobuk-gu,

Cheonan 31172, Korea

Tel: $+82-41-570-1677$

Fax: $+82-41-570-7846$

E-mail: hjchoi@kornu.ac.kr

Received: July 5, 2017

Revised: August 14, 2017

Accepted: August 24, 2017

This work was supported by the National Research Foundation of Korea Grant funded by the Korean Government (NRF-2013S1A5A8023389).
Objectives: Impairment of discourse production ability and cognitive function are known to appear during the stages of amnestic mild cognitive impairment $(\mathrm{aMCl})$ and early stages of Alzheimer's disease (EAD). The purpose of the present study was to investigate the relationship between the ratio of Correct Information Unit (CIU) and cognitive functions in patients with $\mathrm{aMCl}$ and $\mathrm{EAD}$. Methods: Thirty patients with $\mathrm{aMCl}$ and thirty patients with $\mathrm{EAD}$ participated in this study. They took part in attention (Digit Span Test), confrontational naming, memory, and executive function tasks (Color Word Stroop Test [CWST], Trail Making Test [TMT], Controlled Oral Word Association Test [COWAT]). Discourse samples were collected from simple and complex picture description tasks. Results: The results were as follows. First, the ratio of CIU had no significant correlation to age, educational level or Korean-Mini Mental State Examination score in the two groups. Second, there was no significant difference by group in the Digit Span Test, but performances ratios of CIU, confrontational naming, memory and executive function tasks in $\mathrm{aMCl}$ were significant higher than those in EAD. Third, the ratio of $\mathrm{CIU}$ in aMCl had significant correlations to performances of backward digit span, confrontational naming, delayed recall, color reading (reaction time per item) on the Stroop test, and COWAT. Fourth, the ratio of CIU in EAD had significant correlations to performances of backward digit span, confrontational naming, memory, color reading on the Stroop test, and COWAT. Conclusion: These results suggest that the relationship between $\mathrm{CIU}$ and cognitive functions was different in aMCl and EAD.

Keywords: Picture description, Correct Information Unit, Cognitive function, Amnestic mild cognitive impairment, Alzheimer's disease
노인 인구의 증가와 그에 따른 만성 질환의 급증으로 인해 치매 에 대한 관심이 높아지고 있다. 그 중에서도 알츠하이머병(Alzheimer's disease, $\mathrm{AD}$ )은 우리나라에서 치매를 일으키는 원인질환 중 $70 \%$ 이상을 차지하는 것으로 알려져 있다(Korea Ministry for Health and Welfare, 2013). AD 환자는 전반적인 인지기능 및 일상 생활 수행 능력의 손상 이외에도 언어 및 의사소통 장애가 나타나 며, 이와 관련된 연구가 활발히 이루어지고 있다. $\mathrm{AD}$ 환자의 언어 장애와 관련된 연구들을 살펴보면, 초기 단계부터 구어 유창성 (verbal fluency), 청각적 이해력, 읽기 이해력, 담화 능력에 손상을
보이며, 이러한 언어 손상은 표준화된 검사를 통해 검출 가능하다 (Tsantali, Economidis, \& Tsolaki, 2013). 또한, 의미기억 손상과 관 련된 이름대기 장애, 공허한 말(empty speech), 의미 착어(semantic paraphasia) 등이 초기부터 나타나고(Adlam, Bozeat, Arnold, Watson, \& Hodges, 2006; Appell, Kertesz, \& Fisman, 1982; Bayles, Tomoeda, \& Trossset, 1992; Emery, 2000), 구문 능력(Kempler, Curtiss, \& Jackson, 1987), 따라말하기(repetition) 및 조음(articulation) 능력은 대체로 보존된다(Croot, Hodges, Xuereb, \& Patterson, 2000). 이렇듯 $\mathrm{AD}$ 환자의 언어장애는 의미적 측면의 손상이 초기부터 두 
드러지며, 통합적인 언어 산출 능력을 평가할 수 있는 담화 산출 과 제를 사용하면 내용 오류, 단어 찾기 지연, 정보전달 능력의 제한 등을 민감하게 평가할 수 있다고 알려져 있다(Forbes-McKay \& Venneri, 2005).

치매의 전단계로 알려져 있는 경도인지장애(mild cognitive impairment, MCI) (Petersen et al., 2001)의 언어장애와 관련된 연구 는 그 결과가 논쟁적이다. 일부의 연구는 $\mathrm{MCI}$ 단계에서는 대체로 언어 능력이 보존된다고 보고하고 있으며, 일부의 연구에서는 미세 하지만 의미적 언어 능력의 손상이 나타난다고 보고하고 있다(Taler \& Phillips, 2008). 이렇듯 $\mathrm{MCI}$ 의 언어장애와 관련된 연구 결과 가 상반된 이유로는 $\mathrm{MCI}$ 집단의 이질성으로 인한 연구대상의 차이, 사용한 과제의 차이 등으로 설명할 수 있다(Tsantali et al., 2013). $\mathrm{MCI}$ 환자의 미세한 언어장애를 보고한 연구 결과들을 종합하면, 구어 유창성, 이름대기, 청각적 이해력(Ritchie, Artero, \& Touchon, 2001), 담화 산출(discourse production) (Forbes-McKay \& Venneri, 2005) 과제에서 일반 노인과 비교하여 손상을 보인다. 특히, Forbes, Venneri와 Shanks (2001)는 두 장 이상으로 구성되어 있는 연속 그 림을 보고 설명하는 그림설명 과제를 사용하면 정보전달 능력, 의 미 착어, 단어 찾기 지연 등 $\mathrm{MCI}$ 환자의 의미적 측면에서의 언어 손 상이 검출 가능하다고 하였다. 이와 관련된 국내의 연구로 Kim, Kim, Namkoong, Kim과 Kim (2006)은 치매 의심군이 일반 노인 에 비해 발화당 단어수 및 내용어수, Correct Information Unit (CIU) 비율에서 낮은 수행을 보인다고 보고하였으며, Choi, Kim, Lee와 Kim (2013)은 MCI 환자의 CIU 비율이 정상 노인에 비해 유 의하게 낮아 그들의 정보전달 능력에 제한이 있음을 보고하였다.

이렇듯 여러 연구에서 통합적인 의사소통 능력을 평가할 수 있 는 담화 산출 과제는 $\mathrm{AD}$ 뿐 아니라 $\mathrm{MCI}$ 환자의 미세한 언어장애 를 검출하는 데 적합한 과제임을 제시하고 있다. 그림설명 과제를 통한 자발화 분석 기준 중 $\mathrm{MCI}$ 와 $\mathrm{AD}$ 환자를 대상으로 가장 널리 사용되는 것은 CIU 분석이다(Nicholas \& Brookshire, 1993). CIU 는 '문맥상 명료하고, 과제에 적절하며, 정확한 정보를 제공하는 낱 말'로 정의되며, $\mathrm{CIU}$ 수, 분당 $\mathrm{CIU}$ 수, $\mathrm{CIU}$ 비율 등으로 분석된다 (Kwon, Kim, Choi, Na, \& Lee, 1998). 그 중에서 전체 낱말 중 CIU 가 차지하는 비율로 분석하는 CIU 비율은 정보전달의 정확성 및 담화 산출의 효율성을 가장 민감하게 평가할 수 있는 것으로 알려 져 있다(Im, Kwon, \& Sim, 2001; Kim et al., 2006; Kwon et al., 1998). 특히, $\mathrm{MCI}$ 와 $\mathrm{AD}$ 환자를 대상으로 의미적 자발화 분석 척도의 유 용성을 살펴본 Jin, Choi와 Lee (2016)의 연구에 따르면 MCI 집단 이 $\mathrm{AD}$ 집단과 비교하여 $\mathrm{CIU}$ 비율에서만 유의하게 수행이 높은 것 으로 나타나 $\mathrm{CIU}$ 비율 분석은 $\mathrm{MCI}$ 와 $\mathrm{AD}$ 환자의 자발화 산출 능
력의 차이를 가장 정확하고 민감하게 반영하는 분석 척도임을 알 수 있다.

$\mathrm{AD}$ 로 인한 인지기능장애 역시 최근에 각광받는 연구 분야이다. 고령의 $\mathrm{AD}$ 환자의 경우 노화(aging)로 인한 인지기능의 변화와 $\mathrm{AD}$ 로 인한 인지기능장애가 결합되어 보다 뚜렷한 인지기능의 저 하가 나타난다. $\mathrm{AD}$ 환자들에게 나타나는 인지기능 문제는 기억력 장애(Chertkow, \& Bub, 1990), 지남력 장애(Joray, Herrmann, Mulligan, \& Schnider, 2004), 주의력 장애(Perry, \& Hodges, 1999), 시 공간 처리 능력의 제한(Prvulovic et al., 2002), 전두엽 집행기능(executive function)의 손상(Baudic, Dalla Barba, Thibaudet, Smagghe, \& Traykov, 2006) 등을 포함한다. MCI 환자의 경우에는 진단 기준상 기억 이외의 전반적인 인지기능은 정상 수준으로 되어 있으 나 실제적으로는 다양한 인지기능에 미세한 손상이 나타나는 것으 로 알려져 있다(Petersen, 2003). 이와 관련하여 Nordlund 등(2005) 은 인지처리 속도, 학습, 시지각 기능 및 집행기능에서 $\mathrm{MCI}$ 환자의 수행이 일반 노인에 비해 저하된다고 보고하였으며, Ribeiro, de Mendoca와 Guerreiro (2006)는 MCI 환자들은 기억장애 이외에 도 시간적 지남력 장애(68.7\%), 의미 유창성 과제의 어려움(30.2\%), 구어적 문장 이해력 손상 $(33.7 \%)$, 계산 장애(23.4\%), 운동 개시의 곤란(23.9\%) 등의 어려움을 보인다고 보고하였다.

지금까지 살펴본 바와 같이 $\mathrm{MCI}$ 와 $\mathrm{AD}$ 환자는 의사소통 및 인지 기능에 제한을 보이는데, 이 둘은 서로 관련이 있다. 의사소통 상황 에서 적절한 담화를 산출하기 위해서는 언어 능력 이외에 다양한 인지기능이 요구된다(Hinchliffe, Murdoch, Chenery, Baglioni, \& Harding-Clark, 1998). 이와 관련하여 일부 연구에서 뇌손상으로 인한 인지기능 장애와 의사소통 능력 사이의 관련성을 보고하였는 데, 외상성 뇌손상(traumatic brain injury) 환자의 담화산출 능력은 집행기능과 상관을 보였으며(Coelho, 2002), MCI 환자의 담화 산 출 능력은 작업기억과 관련이 있었다(Caspari \& Parkinson, 2000). 그러나 기존의 연구들은 $\mathrm{MCI}$ 및 $\mathrm{AD}$ 환자를 대상으로 한 연구가 제한적이며, 담화 산출 능력과 일부 단편적인 인지기능 사이의 관 련성만 살펴봤을 뿐 주의집중력, 기억력, 집행기능 등 다양한 인지 기능 중 어떠한 기능이 담화 산출 능력과 관련이 있는지를 살펴본 연구는 대단히 제한적이다. 최근에 Choi (2015)는 일반 노인을 대상 으로 정상적인 노화로 인한 담화 산출 능력의 제한과 다양한 인지 기능과의 관련성을 살펴보았다. 이 연구에서는 일반 노인의 그림설 명 과제를 통한 CIU 비율과 이름대기, 주의집중력, 기억력, 집행기 능 등 인지기능 사이의 관련성을 분석하였는데, 그 결과 그림설명 과제의 $\mathrm{CIU}$ 비율은 이름대기 및 집행기능 중 통제단어 연상 과제 의 수행과는 정적 상관이, 교대적 기호 잇기의 수행시간 및 오류수 
와는 부적상관이 나타났다. 즉, 일반 노인의 담화 산출 능력은 노화 로 인한 어휘산출 능력의 제한 및 과제전환 능력과 같은 복합적 집 행기능의 제한과 관련이 있음을 알 수 있다.

본 연구는 Choi (2015) 연구의 후속연구로 $\mathrm{AD}$ 로 진행될 가능성 이 높은 기억상실형 $\mathrm{MCI}$ (amnesticMCI, aMCI)와 초기의 $\mathrm{AD}$ (early stage of $\mathrm{AD}, \mathrm{EAD}$ ) 환자를 대상으로 그림설명 과제의 $\mathrm{CIU}$ 비율 분석을 통한 정보전달 능력과 다양한 인지기능 간의 관련성 을 알아보는 것을 목적으로 하였다. 또한, 동일한 과제를 사용한 Choi (2015)의 연구 결과와 본 연구 결과를 비교함으로써 $\mathrm{aMCI}$ 와 $\mathrm{EAD}$ 환자의 담화 산출 능력과 인지기능과의 관련성이 노화로 인 한 결과와 어떠한 차이를 보이는지 추가적으로 분석할 수 있다. 구 체적인 연구 문제는 다음과 같다. 첫째, $\mathrm{aMCI}$ 및 $\mathrm{EAD}$ 환자의 그림 설명을 통한 $\mathrm{CIU}$ 비율과 연령, 교육년수 및 K-MMSE 점수의 상관 을 알아본다. 둘째, $\mathrm{aMCI}$ 와 $\mathrm{EAD}$ 환자의 그림설명을 통한 $\mathrm{CIU}$ 비 율 및 인지기능(주의집중력, 대면 이름대기, 기억력, 이해력, 전두엽 집행기능) 검사의 수행 차이를 알아본다. 마지막으로 $\mathrm{aMCI}$ 와 $\mathrm{EAD}$ 환자의 그림설명을 통한 $\mathrm{CIU}$ 비율과 인지기능검사 결과와의 상관을 분석한다.

\section{연구방법}

\section{연구대상}

본 연구의 대상은 기억상실형 경도인지장애(aMCI) 환자 30 명(남 성 15 명, 여성 15 명), 초기 알츠하이머병(EAD) 환자 30명(남성 15 명, 여성 15명)이다. 우선 aMCI는 Petersen 등(2001)의 진단기준에 의해 정신과 전문의의 진단을 받은 환자로 (1) 주관적인 기억장애 를 호소하고, (2) 전반적인 인지기능은 정상 범위에 속하며(K-MMSE 점수가 연령과 교육년수 규준[Kang, 2006]에서 -1.0 SD 이상), (3) 일상생활 활동(activity of daily living, $\mathrm{ADL}$ ) 능력이 정상이고(Barthel Index [Mahoney, 1965] 점수 20점), (4) 객관적으로 기억 손상 이 나타나며([Korean version of the Consortium to Establish a Registry for Alzheimer's Disease Assessment Packet, CERAD-K; Lee et al., 2002]의 단어 목록 회상, 단어 목록 재인, 구성 회상 중 하 나 이상의 검사에서 $-1.5 \mathrm{SD}$ 이하), (5) 치매의 진단기준을 만족하지 않는 대상으로 선정하였다. 다음으로 $\mathrm{EAD}$ 는 National Institute of Neurological and Communicative Disorders and Stroke and Alzheimer's Disease and Related Disorders Association (NINCDSADRDA; McKhann et al., 1984)의 진단기준에 따라 정신과 전문의 에 의해 $\mathrm{AD}$ 로 진단받은 환자 중 Clinical Dementia Rating (CDR; Morris, 1993)의 총점이 0.5 이거나 1 인 경우로 선정하였다. $\mathrm{EAD}$ 환
Table 1. Results of age, education level and K-MMSE score by group

\begin{tabular}{lccc}
\hline & aMCl & EAD & Group comparison \\
\hline Age (yr) & $71.17(4.24)$ & $73.60(4.21)$ & aMCl < EAD \\
Education (yr) & $9.33(3.85)$ & $8.17(3.57)$ & aMCl =EAD \\
K-MMSE & $26.17(1.51)$ & $22.73(2.77)$ & aMCl $>$ EAD \\
\hline
\end{tabular}

Values are presented as mean (SD).

$\mathrm{aMCl}=$ amnestic mild cognitive impairment; $\mathrm{EAD}=$ early stage of Alzheimer's disease; K-MMSE = Korean version of Mini-Mental State Examination (Kang, 2006).

자의 $\mathrm{CDR}$ 총점은 0.5 가 13 인, 1 이 17 인이었다.

연구대상이 된 $\mathrm{aMCI}$ 와 $\mathrm{EAD}$ 집단의 연령, 교육년수, $\mathrm{K}-\mathrm{MMSE}$ 점수의 평균과 표준편차와 집단 간 차이를 Table 1 에 제시하였다. 연령, 교육년수, K-MMSE 점수의 집단 간 차이를 알아보기 위한 독 립표본 $t$-검정 결과 집단 간 교육년수에 의한 차이는 유의하지 않았 으나 $(t=1.216, p=.229)$, 연령 평균은 $\mathrm{EAD}$ 환자 집단이 유의하게 높았으며 $(t=-2.233, p=.029), \mathrm{K}-\mathrm{MMSE}$ 점수 평균은 $\mathrm{aMCI}$ 환자 집 단이 유의하게 높았다 $(t=5.967, p<.001)$.

\section{연구과제}

\section{담화 산출}

본 연구에서는 $\mathrm{aMCI}$ 와 $\mathrm{EAD}$ 환자의 담화 산출을 유도하기 위해 그림설명 과제를 사용하였다. 그림설명 과제는 가장 많이 사용되는 담화 산출 과제로 동일한 그림을 사용하기 때문에 분석이 용이하 고, 지속적으로 그림이 제시되어 기억장애의 영향 및 과제에 대한 부담이 적다는 장점을 가진다(Choi, 2011; Duong, Tardif, \& Ska, 2003). 본 연구에서는 Choi (2015)의 연구와 동일한 단일그림(Boston Cookie-Theft picture) (Goodglass \& Kaplan, 1983)과 연속그림 (부부싸움 그림) (Nicholas \& Brookshire, 1993)을 사용하였다. 그 림설명 과제의 분석은 대상자의 정보전달 능력 및 담화 산출의 효 율성을 평가하는 것으로 알려져 널리 사용되고 있는 Correct Information Unit (CIU) 비율(Nicholas \& Brookshire, 1993)을 사용 하였다. 국내 연구에서도 담화 분석의 척도로 CIU 비율 분석이 많 이 이루어졌으며(Choi, 2015; Im et al., 2001; Kwon et al., 1998), 특 히 $\mathrm{CIU}$ 비율 분석은 $\mathrm{MCI}$ 환자의 담화 산출 능력에 있어서의 미세 한 손상을 유용하게 검출해내는 것으로 알려져 있다(Choi et al., 2013; Kim et al., 2006). Choi (2015)의 연구에 따라 30초 이상 산출 된 담화만을 분석 대상으로 하였으며, $\mathrm{CIU}$ 비율은 대상자가 산출 한 전체 어절 중 그림 내용에 적합하다고 판단되는 어절의 비율로 분석하였다. 


\section{인지기능 검사}

주의집중력(Attention)

주의집중력 평가를 위하여 숫자외우기검사(Digit Span Test; Kang, Chin, \& Na, 2002)를 실시하였다. 숫자외우기검사는 숫자를 불러주고 대상자가 바로 혹은 거꾸로 외우도록 하는 검사로 숫자바 로외우기(Forward Digit Span)는 외운 숫자의 총 개수인 9점 만점, 숫자거꾸로외우기(Backward Digit Span)는 거꾸로 외운 숫자의 총 개수인 8점 만점으로 채점하였다.

\section{대면 이름대기(Confrontational naming)}

대면 이름대기 능력 평가를 위하여 우리나라에서 연령과 교육년 수에 따라 표준화되어 있는 한국판 보스톤이름대기검사-A형 병렬 단축형(Kang, Kim, \& Na, 2000) 검사를 실시하였다. 본 검사는 15 문항으로 구성되어 있으며, 본 연구에서는 정반응한 수에 4 배하여 60점을 총점으로 하였다.

\section{기억력(Memory)}

본 연구에서는 기억력 평가를 위해 언어기억검사인 서울언어학 습검사(Seoul Verbal Learning Test, SVLT; Kang \& Na, 2003)를 실 시하였다. SVLT는 12 개의 단어를 포함하고 있으며, 즉각회상(immediate recalls), 지연회상(delayed recalls), 재인(recognition) 검사 로 구성되어 있다. 지연회상은 즉각회상 3 차 시행 후 20 분의 시간 간격을 두고 시행하였으며, 경과 시간 20 분 동안에는 비언어과제를 실시하였다. 즉각회상은 12 점씩 3 회 36 점, 지연회상은 12 점, 재인은 정반응 12 점과 정부정(12-오반응수) 12점 총 24 점 만점으로 하였다.

\section{집행기능(Executive function)}

\section{스트룹 테스트(Stroop Test)}

스트룹 테스트는 집행기능 중 부적절하게 활성화된 정보를 억제 (inhibition)하는 능력을 평가하는 것으로 알려져 있다(Spieler, Balota, \& Faust, 1996). 본 연구에서는 Lee, Kang과 $\mathrm{Na}$ (2000)에 의해 개 발된 Korean-Color Word Stroop Test (K-CWST)를 실시하였다. K-CWST는 색깔과 관계없이 제시된 글자를 읽도록 하는 글자 읽 기 조건과 글자와 상관 없이 색깔을 말하도록 하는 색깔 읽기 조건 2장의 카드로 구성되어 있으며, 두 조건 모두 112점 만점이다. 본 연 구에서는 각 조건 당 정반응수(Word reading: number of correct responses/Color reading: number of correct responses)와 항목 당 반응시간(Word reading: time per item/Color reading: time per item), 조건 간 간섭점수(Interference score)를 측정지표로 하였다.
통제 단어 연상 검사(Controlled Oral Word Association Test)

통제 단어 연상 검사는 집행기능 중 범주별 어휘를 생성하는 구 어 유창성(verbal fluency)을 평가하는 검사로(Baldo, Shimamura, Delis, Kramer, \& Kaplan, 2001), 본 연구에서는 한국판 통제단어연 상검사(Korean version of Controlled Oral Word Association Test, K-COWAT; Kang, Chin, Na, Lee, \& Park, 2000)를 실시하였다. KCOWAT는 의미 유창성(semantic fluency) (동물, 가게물건)과 음소 유창성(phonemic fluency) ('ᄀ', 'O', '人’ 으로 시작되는 낱말)으로 구성되어 있으며, 1 분 동안 생성한 각 범주의 합을 점수로 하였다.

\section{기호잇기검사(Trail Making Test)}

기호잇기검사는 집행기능 중 과제 전환 능력(switching)을 평가 하는 대표적인 검사로 알려져 있다(Vandierendonck, 2000). 본 연구 에서는 인지기능장애를 가진 환자들에게 유용성이 인정된 Tombaugh (2004)의 Trail Making Test (TMT)를 실시하였다. 본 검사 는 Part A와 Part B로 구성되어 있으며 Part A는 숫자 25개를 순서 대로 잇는 검사이며, Part B는 숫자 13개와 문자 12 개를 교대로 연 결하는 검사이다. 측정 지표는 각 Part의 수행시간(초)으로 하였다.

\section{연구절차}

본 연구는 나사렛대학교 생명윤리심의위원회의 승인(14-041729)과 대상자의 동의를 받아 진행하였다. 모든 검사는 심리검사실 에서 개별적으로 실시하였으며, 예비문항을 통하여 대상자가 검사 에 대해 이해하고 있다는 판단 하에 검사를 진행하였다. 대상자 반 응은 동의를 얻어 EDIROL R-09 WAVE/MP3 Recorder로 녹음하 였다. 그림설명 과제의 CIU 비율에 대한 신뢰도는 두 명의 평가자 사이의 평가자 간 신뢰도로 평가하였으며, 수집된 모든 자료에 대 한 CIU 비율의 평가자 간 일치율은 $95 \%$ 이상이었다.

\section{통계분석}

IBM SPSS Statistics 22 프로그램을 이용하여 모든 통계분석을 실시하였다. 우선 연령, 교육년수, K-MMSE 점수에서 $\mathrm{aMCI}$ 와 $\mathrm{EAD}$ 집단 간 차이가 있는지 알아보기 위하여 독립표본 $t$-검정을 실시하 였다. 다음으로 두 집단 간 CIU 비율 및 인지기능검사의 수행 차이 가 있는지 알아보기 위하여 독립표본 $t$-검정을 통해 두 집단 간에 유의한 차이가 있는 것으로 나타난 연령 변수를 공변량으로 한 다 변량 분석을 실시하였다. 마지막으로 $\mathrm{aMCI}$ 와 $\mathrm{EAD}$ 각 집단의 $\mathrm{CIU}$ 비율과 연령, 교육년수, K-MMSE 결과와의 상관을 알아보기 위하 여 상관분석을, $\mathrm{CIU}$ 비율과 인지기능검사 결과와의 상관을 알아 보기 위하여 연령을 통제한 편상관분석을 실시하였다. 


\section{연구결과}

\section{집단에 따른 $\mathrm{CIU}$ 비율과 연령, 교육년수, $\mathrm{K}-\mathrm{MMSE}$ 점수의 상관}

$\mathrm{aMCI}$ 와 $\mathrm{EAD}$ 집단의 $\mathrm{CIU}$ 비율과 연령, 교육년수, K-MMSE 점수 의 상관분석 결과를 Table 2에 제시하였다. 결과를 살펴보면, $\mathrm{aMCI}$ 와 $\mathrm{EAD}$ 두 집단 모두 그림설명 과제에서의 CIU 비율과 연령, 교육 년수, K-MMSE 점수의 상관은 통계적으로 유의하지 않았다.

Table 2. Result of the correlation among age, education, K-MMSE score and ratio of CIU by group

\begin{tabular}{lcc}
\hline & $\mathrm{aMCl}$ & EAD \\
\hline Age & -.249 & -.178 \\
Education & .313 & .216 \\
K-MMSE & .107 & .191 \\
\hline
\end{tabular}

$\mathrm{CIU}=$ Correct Information Unit; $\mathrm{aMCl}=$ amnestic mild cognitive impairment; $\mathrm{EAD}=$ early stage of Alzheimer's disease; K-MMSE=Korean version of Mini-Mental State Examination (Kang, 2006).

\section{집단에 따른 CIU 비율과 인지기능검사 결과의 차이}

$\mathrm{aMCI}$ 와 $\mathrm{EAD}$ 집단에 따른 그림설명 과제에서의 $\mathrm{CIU}$ 비율의 평 균을 Figure 1 에, 인지기능검사 결과의 기술통계치와 공분산분석 의 결과로 나타난 과제별 집단에 따른 차이를 Table 3에 제시하였다.

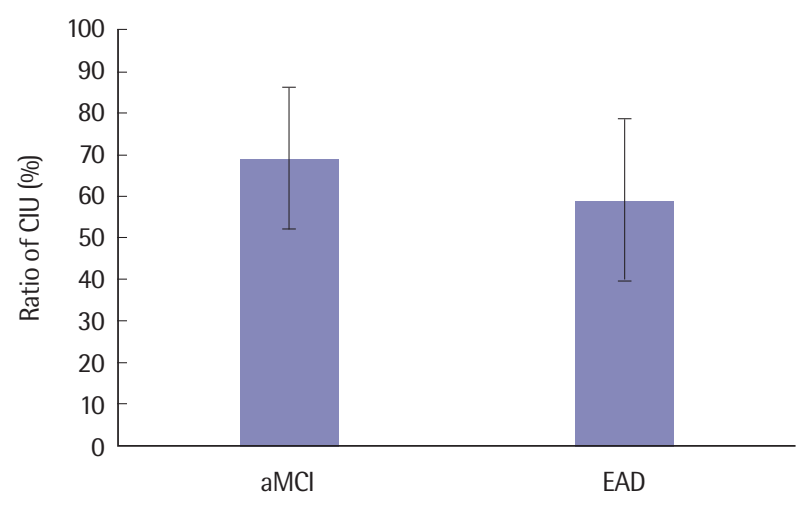

Figure 1. Ratio of Correct Information Unit (CIU) by group. $\mathrm{aMCl}=$ amnestic mild cognitive impairment; $\mathrm{EAD}=$ early stage of Alzheimer's disease.

Table 3. Results of ratio of CIU (\%) and performances on neuropsychological test by group

\begin{tabular}{|c|c|c|c|}
\hline Task & $\mathrm{aMCl}$ & EAD & Group comparison \\
\hline \multicolumn{4}{|l|}{ Attention } \\
\hline Forward Digit Span & $5.40(1.28)$ & $4.97(1.22)$ & $\mathrm{aMCl}=\mathrm{EAD}$ \\
\hline Backward Digit Span & $3.13(.90)$ & $2.97(.99)$ & $\mathrm{aMCl}=\mathrm{EAD}$ \\
\hline \multicolumn{4}{|l|}{ Naming } \\
\hline K-BNT & $42.20(5.76)$ & $32.30(12.05)$ & $\mathrm{aMCl}>\mathrm{EAD}$ \\
\hline \multicolumn{4}{|l|}{ Memory } \\
\hline SVLT immediate recall & $15.63(4.00)$ & $12.83(4.47)$ & $\mathrm{aMCl}>\mathrm{EAD}$ \\
\hline SVLT delayed recall & $4.10(1.52)$ & $2.10(2.19)$ & $\mathrm{aMCl}>\mathrm{EAD}$ \\
\hline Recognition score & $18.57(2.22)$ & $17.20(3.12)$ & $\mathrm{aMCl}=\mathrm{EAD}$ \\
\hline \multicolumn{4}{|l|}{ Executive function } \\
\hline \multicolumn{4}{|l|}{ K-CWST } \\
\hline Word reading: number of correct responses & $105.90(11.66)$ & $97.33(26.00)$ & $\mathrm{aMCl}=\mathrm{EAD}$ \\
\hline Word reading: time per item & $0.91(.27)$ & $1.28(.86)$ & $\mathrm{aMCl}<\mathrm{EAD}$ \\
\hline Color reading: number of correct responses & $62.60(16.84)$ & $51.13(23.76)$ & $\mathrm{aMCl}>\mathrm{EAD}$ \\
\hline Color reading: time per item & $1.97(.67)$ & $2.35(1.10)$ & $\mathrm{aMCl}=\mathrm{EAD}$ \\
\hline Interference score & $1.05(.68)$ & $1.24(.93)$ & $\mathrm{aMCl}=\mathrm{EAD}$ \\
\hline \multicolumn{4}{|l|}{ K-COWAT } \\
\hline Semantics fluency & $28.03(7.88)$ & $19.87(6.28)$ & $\mathrm{aMCl}>\mathrm{EAD}$ \\
\hline Phonemics fluency & $20.30(8.17)$ & $13.53(7.88)$ & $\mathrm{aMCl}>\mathrm{EAD}$ \\
\hline \multicolumn{4}{|l|}{ TMT } \\
\hline Part A: reaction time & 79.07 (43.01) & 135.33 (87.82) & $\mathrm{aMCl}<\mathrm{EAD}$ \\
\hline Part B: reaction time & 286.30 (88.79) & $317.27(77.94)$ & $\mathrm{aMCl}=\mathrm{EAD}$ \\
\hline
\end{tabular}

Values are presented as mean (SD).

$\mathrm{aMCl}=$ amnestic mild cognitive impairment; $\mathrm{EAD}$ = early stage of Alzheimer's disease; $\mathrm{CIU}=$ Correct information unit; K-BNT=Korean version of Boston Naming Test (Kim \& Na, 1997); SVLT = Seoul Verbal Learning Test (Kang \& Na, 2003); K-CWST = Korean version of Color Word Stroop Test (Lee, Kang, \& Na 2000); K-COWAT =Korean version of Controlled Oral Word Association Test (Kang, Chin, Na, Lee, \& Park, 2000); TMT=Trail Making Test (Tombaugh, 2004). 
다변량 분석의 결과 Wilks의 람다는 .499, 유의확률은 .006 으로 집 단에 따른 CIU 비율과 인지기능에 유의한 차이가 있는 것으로 나 타났다. 그림설명 과제에서의 $\mathrm{CIU}$ 비율은 $\mathrm{aMCI}$ 환자 집단이 $\mathrm{EAD}$ 집단에 비해 유의하게 높은 것으로 나타났다 $(F=6.148, p=.016)$.

\section{집단에 따른 CIU 비율과 인지기능검사 결과의 편상관}

연령 변수를 통제한 $\mathrm{aMCI}$ 와 $\mathrm{EAD}$ 집단에 따른 그림설명 과제에 서의 CIU 비율과 인지기능검사와의 편상관분석 결과를 Table 4에 제시하였다. 분석결과, 우선 $\mathrm{aMCI}$ 집단의 $\mathrm{CIU}$ 비율은 주의집중력 중 숫자거꾸로외우기, 이름대기, 기억력검사 중 SVLT 지연회상, 집 행기능검사 중 K-COWAT의 의미 유창성 및 음소 유창성 결과와 는 통계적으로 유의한 정적상관을 보였으며, 집행기능검사 중 KCWST의 색깔읽기 항목 당 반응시간과 간섭점수와는 통계적으로

Table 4. Result of partial correlation among the ratio of CIU and performances on neuropsychological test by group

\begin{tabular}{llc}
\hline \multirow{2}{*}{ Task } & \multicolumn{2}{c}{ Pearson correlation coefficient } \\
\cline { 2 - 3 } & $\mathrm{aMCl}$ & $\mathrm{EAD}$ \\
\hline Attention & & \\
Forward Digit Span & .068 & .112 \\
Backward Digit Span & $.411^{*}$ & $.476^{* *}$ \\
Naming & & \\
K-BNT & $.512^{* *}$ & $.406^{*}$ \\
Memory & & \\
SVLT immediate recall & .066 & $.400^{*}$ \\
SVLT delayed recall & $.370^{*}$ & $.439^{*}$ \\
Recognition score & .317 & $.489^{* *}$ \\
Frontal executive function & & \\
K-CWST & & \\
Word reading: number of correct responses & .124 & .148 \\
Word reading: time per item & -.080 & -.265 \\
Color reading: number of correct responses & .340 & $.477^{* *}$ \\
Color reading: time per item & $-.524^{* *}$ & $-.539^{* *}$ \\
Interference score & $-.537^{* *}$ & $-.590^{* *}$ \\
K-COWAT & & \\
Semantics fluency & $.623^{* *}$ & $.550^{* *}$ \\
Phonemics fluency & $.452^{* *}$ & $.374^{*}$ \\
TMT & & \\
Part A: reaction time & -.084 & -.289 \\
Part B: reaction time & -.204 & -.044 \\
\hline
\end{tabular}

$\mathrm{CIU}=$ Correct information unit; $\mathrm{aMCl}=$ amnestic mild cognitive impairment; $\mathrm{EAD}=$ early stage of Alzheimer's disease; K-BNT = Korean version of Boston Naming Test (Kim \& Na, 1997); SVLT = Seoul Verbal Learning Test (Kang \& Na, 2003); K-CWST = Korean version of Color Word Stroop Test (Lee, Kang, \& Na 2000); K-COWAT = Korean version of Controlled Oral Word Association Test (Kang, Chin, Na, Lee, \& Park, 2000); TMT = Trail Making Test (Tombaugh, 2004).

${ }^{*} p<.05,{ }^{* *} p<.01$.
유의한 부적상관을 보였다. 다음으로, $\mathrm{EAD}$ 집단의 $\mathrm{CIU}$ 비율은 주 의집중력 중 숫자거꾸로외우기, 이름대기, 기억력검사 SVLT의 모 든 항목, 집행기능검사 중 K-CWST의 색깔읽기 정반응수와 KCOWAT의 의미 유창성 및 음소 유창성 결과와는 통계적으로 유 의한 정적상관을 보였으며, 집행기능검사 중 K-CWST의 색깔읽기 항목 당 반응시간과 간섭점수와는 통계적으로 유의한 부적상관을 보였다.

\section{논의 및 결론}

본 연구에서는 $\mathrm{aMCI}$ 와 $\mathrm{EAD}$ 환자를 대상으로 그림설명 과제를 통한 정보전달 능력과 주의집중력, 기억력, 대면 이름대기, 집행기 능 등의 인지기능을 평가하고 이들의 관련성을 알아보았다.

결과를 살펴보면 첫째, $\mathrm{aMCI}$ 와 $\mathrm{EAD}$ 집단의 $\mathrm{CIU}$ 비율과 연령, 교육년수, $\mathrm{K}-\mathrm{MMSE}$ 점수의 상관분석 결과, $\mathrm{aMCI}$ 와 $\mathrm{EAD}$ 두 집단 모두 그림설명 과제의 CIU 비율과 연령, 교육년수, K-MMSE 점수 의 상관은 통계적으로 유의하지 않았다. 즉, $\mathrm{aMCI}$ 와 $\mathrm{EAD}$ 환자 모 두 담화 상황에서 정확히 정보를 전달하는 능력은 성별이나 교육 년수, 선별적인 수준의 인지기능과는 관련성이 낮은 것으로 해석할 수 있다. 이러한 결과는 일반 노인을 대상으로 한 연구 결과들과 다 소 상반되는 결과이다. 대부분의 연구에서 일반 노인의 정보전달 능력은 성별과는 유의한 상관이 없으나, 교육년수, 선별적 수준의 인지기능검사 결과와는 유의한 상관이 있는 것으로 보고되고 있다 (Ardila \& Rosselli, 1996: Choi, 2015; Mackenzie, 1999). 이렇듯 일 반 노인을 대상으로 한 결과와 본 연구의 결과가 차이가 있는 것은 본 연구의 대상이 된 $\mathrm{aMCI}$ 와 $\mathrm{EAD}$ 환자는 정상적인 노화로 인한 인지기능의 저하와는 뚜렷이 구별되는 다양한 인지기능장애를 가 지고 있어, 정보전달 능력과 교육년수나 선별적인 수준의 인지기능 검사 수행 결과와의 상관이 일반 노인에 비해 다소 낮게 나타난 것 으로 해석할 수 있다.

둘째, $\mathrm{aMCI}$ 와 $\mathrm{EAD}$ 집단 간 $\mathrm{CIU}$ 비율과 인지기능검사 수행의 차이를 분석한 결과, 그림설명 과제에서의 $\mathrm{CIU}$ 비율은 $\mathrm{aMCI}$ 환자 집단이 $\mathrm{EAD}$ 집단에 비해 유의하게 높은 것으로 나타났다. 이러한 결과는 $\mathrm{CIU}$ 비율 분석을 통한 $\mathrm{aMCI}$ 환자의 정보전달 능력의 제한 을 주장한 기존의 대부분의 연구 결과들(Choi et al., 2013; ForbesMcKay \& Venneri, 2005; Kim et al., 2006)과 일치한다. 이러한 결과 는 $\mathrm{aMCI}$ 나 $\mathrm{EAD}$ 환자 모두 아직은 어휘-의미 처리 손상에 국한된 언어장애를 보이지만 그들의 손상에는 수준의 차이가 있음을 알 수 있다(Taler \& Phillips, 2008). 이와 관련하여 Forbes 등(2001)은 그림설명 과제를 통하여 $\mathrm{MCI}$ 및 $\mathrm{EAD}$ 환자의 담화 산출 능력을 일 
반 노인과 비교할 경우 $\mathrm{AD}$ 환자는 단일그림만으로도 충분히 담화 손상이 드러나지만 $\mathrm{MCI}$ 환자에게는 여러 장으로 구성된 보다 복 잡한 그림과제를 사용할 것을 제안하였는데, 이는 $\mathrm{MCI}$ 와 $\mathrm{EAD}$ 환 자의 정보전달 능력에 차이가 있다는 본 연구의 결과를 뒷받침한다.

셋째, $\mathrm{aMCI}, \mathrm{EAD}$ 집단 간 인지기능검사 결과의 차이를 살펴보 면, 숫자외우기검사, SVLT의 재인 점수, TMT Part B의 반응시간과 $\mathrm{K}-\mathrm{CWST}$ 의 단어읽기 정반응, 색깔읽기 항목 당 반응시간, 간섭점 수에서는 집단 간 차이가 유의하기 않은 것으로 나타났다. 즉, 주의 집중력, 언어기억의 재인 능력, 집행기능 중 과제전환 능력 및 억제 기능의 일부에서 두 집단 간차이가 나타나지 않았다. 이렇듯 $\mathrm{aMCI}$, $\mathrm{EAD}$ 집단 간 일부의 인지기능에서 유의한 차이가 나타나지 않은 결과는 다소 역설적으로 보이지만, 실제로 본 연구에는 $\mathrm{CDR}$ 총점 이 0.5 의 아주 경도의 $\mathrm{AD}$ 환자들을 다수 포함하고 있기 때문에 그 차이가 유의하지 않은 것으로 여겨진다. 본 연구와 유사하게 경도 의 $\mathrm{AD}$ 환자들을 대상으로 한 일부의 연구에서 유사한 결과를 보 고하고 있다(Lambon, Patterson, Graham, Dawson, \& Hodges, 2003; Nordlund et al., 2005; Petersen et al., 1999). 반면에 K-BNT, K-COWAT, SVLT의 즉각회상, 지연회상, TMT Part A의 반응시간, K-CWST의 단어읽기 항목 당 반응시간, 색깔읽기 정반응에서의 수행은 $\mathrm{aMCI}$ 환자가 $\mathrm{EAD}$ 환자에 비해 유의하게 높은 것으로 나 타났다. 즉, 이름대기, 구어 유창성과 같은 의미적 측면의 언어관련 영역과 기억력, 일부 집행기능검사는 $\mathrm{aMCI}$ 와 $\mathrm{EAD}$ 를 민감하게 변 별해냈다. 이러한 결과 중 언어관련 영역에서의 $\mathrm{aMCI}$ 와 $\mathrm{EAD}$ 환자 의 수행 차이는 앞에서 설명한 의미적 측면의 언어처리에서의 두 집단의 격차로(Forbes et al., 2001; Taler \& Phillips, 2008), 기억능력 및 보다 복잡한 집행기능에서 $\mathrm{aMCI}$ 와 $\mathrm{EAD}$ 두 집단 간 수행 차이 (Petersen et al., 1999)에 기인한 것으로 예측할 수 있다.

다음으로 본 연구의 핵심적인 연구문제인 $\mathrm{aMCI}$ 와 $\mathrm{EAD}$ 환자의 그림설명 과제에서의 $\mathrm{CIU}$ 비율과 인지기능검사와의 상관분석 결 과를 살펴보면, 우선 $\mathrm{aMCI}$ 집단의 $\mathrm{CIU}$ 비율은 주의집중력 중 숫자 거꾸로외우기, 이름대기, 기억력검사 중 SVLT의 지연회상, 집행기 능검사 중 K-CWST의 색깔읽기 항목 당 반응시간과 간섭점수, KCOWAT의 수행과 유의한 상관을 보였다. 즉, $\mathrm{aMCI}$ 환자의 정보전 달 능력은 이름대기나 구어 유창성과 같은 의미적 측면의 언어 능 력, 지연기억, 복잡한 수준의 집행기능과 관련이 있었다. 이와 관련 하여 Duong, Whitehead, Hanratty와 Chertkow (2006)는 MCI 환 자의 언어문제는 의미적인 측면에 국한되어 나타나며, 이러한 의미 적 측면의 언어장애는 복합적인 능력을 요구하는 집행기능이나 의 미처리 과정에 영향을 주는 억제기능에 기인한다고 하였다. 즉, 의 미적 측면의 언어적 손상, K-CWST의 단어읽기 조건보다 복잡한
집행기능 및 억제기능을 잘 반영하는 것으로 알려져 있는(Jensen \& Rohwer, 1966) 색깔읽기 항목 당 반응시간과 간섭점수, 숫자바로 따라외우기에 비해 보다 복잡한 집행기능(GrÉGoire \& Van Der Linden, 1997) 및 작업기능(working memory) (Hester, Kinsella, \& Ong, 2004)을 요구하는 것으로 알려져 있는 숫자거꾸로외우기의 수행이 $\mathrm{aMCI}$ 환자의 정보전달 능력과 관련이 있음을 알 수 있다. 기억력검사중 즉각기억이나 재인에 비해 지연회상 과제만이 $\mathrm{aMCI}$ 환자의 정보전달 능력과 관련이 있다고 나타난 본 연구의 결과는 $\mathrm{aMCI}$ 환자의 경우 지연회상 능력의 저하가 두드러지기 때문인 것 으로 생각해볼 수 있다(Rabin et al., 2009). 다음으로, EAD 집단의 $\mathrm{CIU}$ 비율은 주의집중력 중 숫자거꾸로외우기, 이름대기, 기억력 검 사인 SVLT의 모든 항목, 집행기능검사 중 K-CWST의 색깔읽기 정 반응수 및 항목 당 반응시간과 간섭점수, K-COWAT의 수행과 관 련이 있는 것으로 나타났다. 즉, $\mathrm{EAD}$ 환자의 정보전달 능력은 숫자 바로따라외우기 및 K-CWST의 단어읽기 조건을 제외한 모든 인지 기능과 유의한 상관이 나타났다. 이는 앞서 설명했듯이 숫자바로따 라외우기 및 단어읽기 조건의 스트룹검사가 집행기능을 상대적으 로 정확하게 반영하지 못한다는 점을 고려하면 $\mathrm{EAD}$ 환자의 정보 전달 능력은 거의 모든 인지기능과 유의한 상관이 나타났음을 알 수 있다. 또한, 이름대기나 구어 유창성과 같은 의미적 측면의 언어 능력을 제외한 나머지 인지기능의 경우 CIU 비율과의 상관계수는 $\mathrm{aMCI}$ 환자에 비해 $\mathrm{EAD}$ 환자에게서 더 높았는데, 이러한 결과는 $\mathrm{CIU}$ 비율과 인지기능과의 관련성은 $\mathrm{aMCI}$ 환자에 비해 $\mathrm{EAD}$ 환자 에게서 더 밀접하게 나타남을 알 수 있다. 본 연구에서 사용된 TMT 의 경우 $\mathrm{aMCI}$ 와 $\mathrm{EAD}$ 두 집단 모두 허용하는 제한 시간을 넘겨 검 사를 중단한 환자들의 수가 상당하여 의미 있는 분석이 이루어지 지 못했다. 두 집단 모두 TMT 점수가 CIU 비율과 유의한 상관이 나타나지 않은 결과 역시 이러한 제한점과 관련이 있을 것으로 여 겨진다.

지금까지 $\mathrm{aMCI}$ 와 $\mathrm{EAD}$ 환자의 정보전달 능력과 인지기능의 관 련성을 살펴보았는데, 이러한 결과를 일반 노인을 대상으로 정보전 달 능력과 인지기능의 관련성을 살펴본 Choi (2015)의 연구 결과와 비교하면 다음과 같은 결론을 얻을 수 있다. Choi (2015)의 연구에 서 일반 노인의 정보전달 능력은 노화로 인한 어휘 산출 능력의 제 한 및 과제 전환 능력과 같은 복합적 집행기능의 제한과 관련이 있 었다. $\mathrm{aMCI}$ 환자는 이러한 노화로 인한 변화와 더불어 지연기억 및 작업기억과 같은 기억 능력의 저하와 억제기능을 포함한 복합적 집 행기능 수행의 저하로 인해, $\mathrm{EAD}$ 환자는 기억력, 언어 능력, 집행기 능 등 전반적인 인지기능의 저하로 인해 정보전달 능력이 제한됨을 알수 있다. 
본 연구는 $\mathrm{aMCI}$ 및 $\mathrm{EAD}$ 환자를 대상으로 정보전달 능력의 제 한이 주의집중력, 이름대기, 기억력, 집행기능 등 다양한 인지기능 중 어떠한 기능과 관련이 있는지 면밀히 살펴보고, 정상적인 노화 로 인한 결과와 직접적으로 비교했다는 점에서 의의를 가진다. 다 만, 사용된 담화 과제가 그림설명 과제에 국한되어 실제적인 의사 소통 상황을 정확히 반영하지 못한 점, $\mathrm{aMCI}$ 를 보다 세분화하여 평가하지 못한 점 등이 아쉬움으로 남는다. 앞으로는 실제적인 의 사소통 상황에서의 정보전달 능력을 평가할 수 있는 다양한 과제 와 분석척도를 사용하고, $\mathrm{aMCI}$ 를 단일영역(single domain) aMCI 와 다발영역(multiple domains) aMCI로 보다 세분화하여 정보전 달 능력과 인지기능과의 관련성을 살펴보는 연구가 진행되기를 기 대한다.

\section{REFERENCES}

Adlam, A. L. R., Bozeat, S., Arnold, R., Watson, P., \& Hodges, J. R. (2006). Semantic knowledge in mild cognitive impairment and mild Alzheimer's disease. Cortex, 42, 675-684.

Appell, J., Kertesz, A., \& Fisman, M. (1982). A study of language functioning in Alzheimer patients. Brain and Language, 17, 73-91.

Ardila, A., \& Rosselli, M. (1996). Spontaneous language production and aging: sex and educational effects. International Journal of Neuroscience, 87, 71-78.

Baldo, J. V., Shimamura, A. P., Delis, D. C., Kramer, J., \& Kaplan, E. (2001). Verbal and design fluency in patients with frontal lobe lesions. Journal of the International Neuropsychological Society, 7, 586-596.

Baudic, S., Dalla Barba, G., Thibaudet, M. C., Smagghe, A., Remy, P., \& Traykov, L. (2006). Executive function deficits in early Alzheimer's disease and their relations with episodic memory. Archives of Clinical Neuropsychology, 21, 15-21.

Bayles, K. A., Tomoeda, C. K., \& Trossset, W. (1992). Relation of linguistic abilities of Alzheimer's patients to stage of disease. Brain and Language, 42, $454-472$

Caspari, I., \& Parkinson, S. R. (2000). Effects of memory impairment on discourse. Journal of Neurolinguistics, 13, 15-36.

Chertkow, H., \& Bub, D. (1990). Semantic memory loss in dementia of Alzheimer's type. Brain, 113, 397-417.

Choi, H. (2011). Detecting language deficits in patients with mild cognitive impairment through verbal fluency and picture description tasks. Communication Sciences and Disorders, 16, 171-184.
Choi, H. (2015). Ratio of Correct Information Unit and cognitive functions in healthy elderly adults. Communication Sciences and Disorders, 20, 435445.

Choi, H., Kim, J. H., Lee, C. M., \& Kim, J. I. (2013). Features of semantic language impairment in patients with amnestic mild cognitive impairment. Dementia and Neurocognitive Disorders, 12, 33-40.

Coelho, C. A. (2002). Story narratives of adults with closed head injury and non-brain-injured adults influence of socioeconomic status, elicitation task, and executive functioning. Journal of Speech, Language, and Hearing Research, 45, 1232-1248.

Croot, K., Hodges, J. R., Xuereb, J., \& Patterson, K. (2000). Phonological and articulatory impairment in Alzheimer's disease: a case series. Brain and Language, 75, 277-309.

Duong, A., Tardif, A., \& Ska, B. (2003). Discourse about discourse: what is it and how does it progress in Alzheimer's disease? Brain and Cognition, 53, 177-180.

Duong, A., Whitehead, V., Hanratty, K., \& Chertkow, H. (2006). The nature of lexicosemantic processing deficits in mild cognitive impairment. Neuropsychologia, 44, 1928-1935.

Emery, V. O. B. (2000). Language impairment in dementia of the Alzheimer type: a hierarchical decline? International Journal of Psychiatric Medicine, $30,145-164$.

Forbes-McKay, K. E., \& Venneri, A. (2005). Detecting subtle spontaneous language decline in early Alzheimer's disease with a picture description task. Neurological Sciences, 26, 243-254.

Forbes, K. E., Venneri, A., \& Shanks, M. F. (2001). Distinct patterns of spontaneous speech deterioration: an early predictor of Alzheimer's disease. Brain and Cognition, 48, 356-361.

Goodglass, H., \& Kaplan, E. (1983). The assessment aphasia and related disorders (2nd ed.). Philadelphia, PA: Lea and Febiger.

GrÉGoire, J., \& Van Der Linden, M. (1997). Effect of age on forward and backward digit spans. Aging, Neuropsychology, and Cognition, 4, 140-149.

Hester, R. L., Kinsella, G. J., \& Ong, B. (2004). Effect of age on forward and backward span tasks. Journal of the International Neuropsychological Society, 10, 475-481.

Hinchliffe, F. J., Murdoch, B. E., Chenery, H. J., Baglioni, A. J., \& Harding-Clark, J. (1998). Cognitive-linguistic subgroups in closed-head injury. Brain Inju$r y, 12,369-398$.

Im, E., Kwon, M., \& Sim, H. (2001). The informativeness and efficiency of the connected speech samples in Korean fluent aphasics. Communication 
Sciences and Disorders, 6, 374-391.

Jensen, A. R., \& Rohwer, W. D. (1966). The Stroop color-word test: a review. Acta Psychologica, 25, 36-93.

Jin, C., Choi, H., \& Lee, J. Y. (2016). Usefulness of spontaneous speech analysis scales in patients with mild cognitive impairment and dementia of Alzheimer's type. Communication Sciences and Disorders, 21, 284-294.

Joray, S., Herrmann, F. C. O., Mulligan, R., \& Schnider, A. (2004). Mechanism of disorientation in Alzheimer's disease. European Neurology, 52, 193-197.

Kang, Y. W. (2006). A normative study of the Korean-Mini Mental State Examination (K-MMSE) in the elderly. Korean Journal of Psychology, 25, 1-12.

Kang, Y. W., \& Na, D. L. (2003). Seoul Verbal Learning Test (SVLT). Seoul: Human Brain Research \& Consulting Co.

Kang, Y., Chin, J., \& Na, D. L. (2002). A normative study of the Digit Span Test for the elderly. Korean Journal of Clinical Psychology, 21, 911-922.

Kang, Y., Chin, J., Na, D. L., Lee, J., \& Park, J. S. (2000). A normative study of the Korean version of Controlled Oral Word Association Test (COWAT) in the elderly. The Korean Journal of Psychology, 19, 385-392.

Kang, Y., Kim, H., \& Na, D. L. (2000). Parallel short forms for the KoreanBoston Naming Test (K-BNT). Journal of the Korean Neurological Association, 18, 144-150.

Kempler, D., Curtiss, S., \& Jackson, C. (1987). Syntactic preservation in Alzheimer's disease. Journal of Speech and Hearing Research, 30, 343-350.

Kim, J., Kim, H., Namkoong, K., Kim, S., \& Kim, D. (2006). Spontaneous speech traits in patients with Alzheimer's disease. Communication Sciences and Disorders, 11, 82-98.

Korea Ministry for Health and Welfare. (2013). Nationwide study on the prevalence of dementia in Korea elders. Seoul: Ministry for Health and Welfare. Available from: http://www.mohw.go.kr

Kwon, M., Kim, H., Choi, S., Na, D. L., \& Lee, K. (1998). A study for analyzing spontaneous speech of Korean adults with CIU scoring system. Communication Sciences and Disorders, 3, 35-49.

Lambon Ralph, M. A., Patterson, K., Graham, N., Dawson, K., \& Hodges, J. R. (2003). Homogeneity and heterogeneity in mild cognitive impairment and Alzheimer's disease: a cross-sectional and longitudinal study of 55 cases. Brain, 126, 2350-2362.

Lee, J. H., Lee, K. U., Lee, D. Y., Kim, K. W., Jhoo, J. H., Kim, J. H., ... \& Woo, J. I. (2002). Development of the Korean version of the Consortium to Establish a Registry for Alzheimer's Disease Assessment Packet (CERAD-K) Clinical and Neuropsychological Assessment Batteries. The Journals of Gerontology Series B: Psychological Sciences and Social Sciences, 57, 47-53.
Lee, J., Kang, Y., \& Na, D. L. (2000). Efficiencies of Stroop interference indexes in healthy older adults and dementia patients. Korean Journal of Clinical Psychology, 19, 807-818.

Mackenzie, C. (1999). Adult spoken discourse: the influences of age and education. International Journal of Language and Communication Disorders, $35,269-285$.

Mahoney, F. I. (1965). Functional evaluation: the Barthel index. Maryland State Medical Journal, 14, 61-65.

McKhann, G., Drachman, D., Folstein, M., Katzman, R., Price, D., \& Stadlan, E. M. (1984). Clinical diagnosis of Alzheimer's disease report of the NINCDSADRDA Work Group under the auspices of Department of Health and Human Services Task Force on Alzheimer's disease. Neurology, 34, 939939.

Morris, J. C. (1993). The Clinical Dementia Rating (CDR): current version and scoring rules. Neurology, 43, 2412-2414.

Nicholas, L. E., \& Brookshire, R. H. (1993). A system for quantifying the informativeness and efficiency of the connected speech of adults with aphasia. Journal of Speech, Language, and Hearing Research, 36, 338-350.

Nordlund, A., Rolstad, S., Hellström, P., Sjögren, M., Hansen, S., \& Wallin, A. (2005). The Goteborg MCI study: mild cognitive impairment is a heterogeneous condition. Journal of Neurology, Neurosurgery and Psychiatry, 76, 1485-1490.

Perry, R. J., \& Hodges, J. R. (1999). Attention and executive deficits in Alzheimer's disease. Brain, 122, 383-404.

Petersen, R. C. (2003). Mild cognitive impairment: aging to Alzheimer's disease. New York, NY: Oxford University Press.

Petersen, R. C., Doody, R., Kurz, A., Mohs, R. C., Morris, J. C., Rabins, P. V., ... \& Winblad, B. (2001). Current concepts in mild cognitive impairment. Archives of Neurology, 58, 1985-1992.

Petersen, R. C., Smith, G. E., Waring, S. C., Ivnik, R. J., Tangalos, E. G., \& Kokmen, E. (1999). Mild cognitive impairment: clinical characterization and outcome. Archives of Neurology, 56, 303-308.

Prvulovic, D., Hubl, D., Sack, A. T., Melillo, L., Maurer, K., Frölich, L., ... \& Dierks, T. (2002). Functional imaging of visuospatial processing in Alzheimer's disease. Neuroimage, 17, 1403-1414.

Rabin, L. A., Paré, N., Saykin, A. J., Brown, M. J., Wishart, H. A., Flashman, L. A., ... \& Santulli, R. B. (2009). Differential memory test sensitivity for diagnosing amnestic mild cognitive impairment and predicting conversion to Alzheimer's disease. Aging, Neuropsychology, and Cognition, 16, 357-376. Ribeiro, F., de Mendonça, A., \& Guerreiro, M. (2006). Mild cognitive impair- 
ment: deficits in cognitive domains other than memory. Dementia and Geriatric Cognitive Disorders, 21, 284-290.

Ritchie, K., Artero, S., \& Touchon, J. (2001). Classification criteria for mild cognitive impairment: a population-based validity study. Neurology, 56, $37-42$.

Spieler, D. H., Balota, D. A., \& Faust, M. E. (1996). Stroop performance in healthy younger and older adults and in individuals with dementia of the Alzheimer's type. Journal of Experimental Psychology: Human Perception and Performance, 22, 461-479.

Taler, V., \& Phillips, N. A. (2008). Language performance in Alzheimer's dis- ease and mild cognitive impairment: a comparative review. Journal of Clinical and Experimental Neuropsychology, 30, 501-556.

Tombaugh, T. N. (2004). Trail Making Test A and B: normative data stratified by age and education. Archives of Clinical Neuropsychology, 19, 203-214.

Tsantali, E., Economidis, D., \& Tsolaki, M. (2013). Could language deficits really differentiate Mild Cognitive Impairment (MCI) from mild Alzheimer's disease? Archives of Gerontology and Geriatrics, 57, 263-270.

Vandierendonck, A. (2000). Executive functions and task switching. Psychologica Belgica, 40, 211-226. 


\section{국문초록}

\section{기억상실형 경도인지장애와 초기 알츠하이머병 환자의 정보전달 능력과 인지기능과의 상관 최현주 ${ }^{1} \cdot$ 이준영 \\ ${ }^{1}$ 나사렛대학교 언어치료학과, ${ }^{2}$ 서울대학교의과대학 정신과교실·서울특별시보라매병원 정신건강의학과}

배경 및 목적: 담화 산출 능력의 저하와 인지기능의 손상은 기억상실형 경도인지장애와 초기 알츠하이머병 환자에게서 나타난다. 본 연구는 기억상실형 경도인지장애와 초기 알츠하이머병 환자를 대상으로 정보전달 능력과 인지기능의 관련성을 살펴보는 것을 목적으 로 하였다. 방법: 본 연구는 기억상실형 경도인지장애 환자 30 명과 초기 알츠하이머병 환자 30 명을 대상으로 하였다. 정보전달 능력은 단일그림과 연속그림의 그림설명 과제를 통한 Correct Information Unit (CIU) 비율로, 인지기능은 주의집중력, 대면 이름대기, 기억력, 집행기능검사를 사용하여 평가하였다. 결과: 첫째, 두 집단 모두 CIU 비율은 연령, 교육년수, K-MMSE 점수와는 유의한 상관이 나타나 지 않았다. 둘째, 숫자외우기검사와 일부의 집행기능검사에서는 집단 간 차이가 유의하지 않았으나, CIU 비율, 대면 이름대기, 기억력, 일부 집행기능검사에서는 기억상실형 경도인지장애 환자들의 수행이 초기 알츠하이머병 환자들에 비해 유의하게 높았다. 셋째, 기억상 실형 경도인지장애 환자들의 CIU 비율은 주의집중력 중 숫자거꾸로말하기, 대면 이름대기, 지연기억, 스트룹검사의 색깔 읽기 항목 당 반응시간과 통제단어 연상의 수행력과 유의한 상관을 보였다. 넷째, 초기 알츠하이머병 환자의 CIU 비율은 주의집중력 중 숫자거꾸로 말하기, 대면 이름대기, 기억력, 스트룹검사의 색깔 읽기 정반응수 및 항목 당 반응시간, 통제단어 연상의 수행력과 유의한 상관을 보였 다. 논의 및 결론: 본 연구의 결과는 기억상실형 경도인지장애와 초기 알츠하이머병 환자의 정보전달 능력과 인지기능의 관련성은 서로 상이함을 시사한다.

핵심어: 그림설명, 정보전달, 인지기능, 기억상실형 경도인지장애, 알츠하이머병

이 논문은 2013년 정부(교육과학기술부)의 재원으로 한국연구재단의 지원을 받아 수행된 연구임(NRF-2013S1A5A8023389).

\section{참고문헌}

강연욱(2006). K-MMSE(Korean-Mini Mental State Examination)의 노인 규준 연구. 한국심리학회지, 25, 1-12.

강연욱, 김향희, 나덕렬(2000). 한국판 보스톤 이름대기 검사(K-BNT)의 병렬 단축형 개발. 대한신경과학회지, 18, 144-150.

강연욱, 나덕렬(2003). 서울언어학습검사(SVLT). 서울: 휴브알엔씨.

강연욱, 진주희, 나덕렬(2002). 숫자 외우기 검사(Digit Span Test)의 노인 규준 연구. 한국심리학회지: 임상, 21, 911-922.

강연욱, 진주희, 나덕렬, 이정희, 박재설(2002). 통제 단어 연상 검사(Controlled Oral Word Association Test)의 노인 규준 연구. 한국심리학회지: 임상,

19,385-392.

권미선, 김향희, 최상숙, 나덕렬, 이광호(1998). 한국 성인의 자발화 분석에 관한 연구: CIU분석법을 중심으로. 언어청각장애연구, 3, 35-49.

김정완, 김향희, 남궁기, 김세주, 김덕용(2006). 알츠하이머형 치매환자의 발화특성. 언어청각장애연구, 11, 82-98.

보건복지부(2013). 2012년 전국 치매 역학 조사. 서울: 보건복지부. Available from: http://www.mohw.go.kr.

이정희, 강연욱, 나덕렬. (2000). Stroop 간섭 지표들의 효율성 비교: 정상노인집단과 치매집단을 대상으로. 한국심리학회지: 임상, 19, 807-818.

임은주, 권미선, 심현섭(2001). 경중도에 따른 유창성 실어증환자의 정보전달능력에 관한 연구. 언어청각장애연구, 6, 374-391.

진천, 최현주, 이준영(2016). 경도인지장애 및 알츠하이머형 치매 환자의 자발화 분석 척도의 유용성. 언어청각장애연구, 21, 284-294.

최현주(2011). 구어유창성과 그림설명과제를 통한 경도인지장애(MCI) 환자의 언어손상 검출. 언어청각장애연구, 16, 171-184.

최현주(2015). 일반 노인의 정보전달 능력과 인지기능과의 상관. 언어청각장애연구, 20,435-445.

최현주, 김지현, 이창민, 김재일(2013). 기억형 경도인지장애 환자의 의미적 측면에서의 언어장애 특성. 대한치매학회지, 12, 33-40. 